\title{
A FUNDAÇÃO DA ESTÉTICA COMO DIMENSÃO DA MENTE HUMANA EM KANT
}

\section{The foundation of the aesthetic one as dimension of the mind human being in Kant}

Jairo Dias Carvalho ${ }^{1}$

Resumo

Pretendemos estudar a gênese do problema da passagem do domínio dos conceitos de natureza ao domínio do conceito de liberdade nas duas Introduções da Crítica da Faculdadedo Juízo. Esse problema pare ser a necessidade sentida por Kant de se construir uma receptividade média do ânimo, tendo em vista a sensibilização deste à lei moral. A construção dessa receptividade transcendental é a construção da dimensão estética da mente humana. Ao unir a legalidade do entendimento e da razão por meio da legislação da faculdade de julgar reflexiva, Kant constrói um terceiro termo na tópica das faculdades superiores da mente humana.

Palavras-chave: Kant; Crítica da Faculdade do Juízo; Estética; Mente; Receptividade transcendental.

\section{Abstract}

We intend to study the genesis of the problem of the shift from the realm of concepts of Nature to the realm of concept of freedom in both introductions to the Critique of Judgment. This problem seems to be the need Kant felt to construct an average receptivity of the spirit considering its sensitivity to moral law. The construction of this transcendental receptivity is the construction of the human mind's aesthetic dimension. By joining the legality of understanding to that of reason by means of the legislation of reflexive judgment, Kant constructs a third term in the topic of the human mind's superior faculties.

Keywords: Kant; Critique ofJudgment; Aesthetic; Transcendental receptivity.

1 Doutor. Professor. Departamento de Filosofia, Universidade Federal de Uberlândia.

E-mail: jairodiascarvalho@bol.com.br

Revista de Filosofia, Curitiba, v. 18 n.21, p. 11-25, jul./ dez. 2005. 
No parágrafo III da Primeira Introdução à Crítica da Faculdade do Juízo, Kant admite três faculdades do ânimo, a faculdade-de-conhecer, o sentimento de prazer e desprazer e a faculdade-de-apetição. A diferença entre elas baseia-se na distinção entre suas respectivas representações. Na medida em que se referem ao objeto e à unidade da apercepção, elas pertencem ao conhecimento; na medida em que as representações são consideradas como causa da efetividade desse objeto, elas pertencem à faculdade de apetecer, e na medida em que as representações se referem ao sujeito e conservam sua existência nele, elas pertencem ao sentimento de prazer e desprazer. 0 tipo de relação estabelecida pelas representações define, portanto, três diferentes faculdades do ânimo.

Entre as questões da sensibilização do ânimo à razão prática e da efetivação dos efeitos da liberdade no mundo, se situa a discussão (da qual depende a autonomização do sentimento) da vinculação do sentimento de prazer às faculdades de apetecer e conhecer. Esta questão, posta na origem da crítica do gosto, é expressa na Primeira Introdução:

Ora, consegue-se por certo descobrir entre o sentimento de prazer e as duas outras faculdades uma vinculação a priori e, se vinculamos um conhecimento a priori, ou seja, o conceito racional da liberdade, com a faculdade-de-desejar como seu fundamento-de-determinação, encontrar nessa determinação objetiva, ao mesmo tempo, subjetivamente, um sentimento de prazer contido na determinação da vontade. Mas desse modo não é por intermédio do prazer ou desprazer que a faculdade de conhecimento está ligada com a faculdade-de-desejar; pois este não a precede, mas, ou se segue diretamente à determinação desta última ou, talvez, nada mais é do que a sensação dessa determinabilidade da vontade pela própria razão, portanto absolutamente não é um sentimento particular e uma receptividade peculiar que exigisse, entre as propriedades da mente, uma divisão particular. E, como no desmembramento das faculdades da mente em geral está dado incontestavelmente um sentimento de prazer, que, independente da determinação da faculdade de desejar, pode, antes, fornecer um fundamento-de-determinação da mesma, embora, para sua vinculação com as outras duas faculdades em um sistema, seja exigido que esse sentimento de prazer, assim, como as outras faculdades, não repouse sobre fundamentos meramente empíricos, mas também sobre princípios a priori, então, para a Idéia da filosofia como um sistema será também requerida (embora não uma doutrina, no entanto) uma crítica do sentimento de prazer e desprazer, na medida em que não está fundado empiricamente (KANT, 1995, p. 42).

Revista de Filosofia, Curitiba, v. 18 n. 21, p. 11-25, jul./dez. 2005. 
Examinando com atenção esta passagem, vemos de início que ela nos explica como a exigência de sistematização guiada pela tábua das faculdades levou à construção de uma nova crítica, a crítica do sentimento chamada de crítica do gosto na carta a Reinhold ${ }^{2}$. Um dos motivos para isto é o recobrimento entre as questões do gosto e do sentimento, desde a obra pré-crítica “Observações acerca do Belo e do Sublime". Trata-se como diz o início da passagem citada, não de um sentimento qualquer, mas do sentimento de prazer. $\mathrm{O}$ prazer é um sentimento e sentir prazer é uma questão de gosto, sendo o gosto uma faculdade de apreciação de prazer. O gosto repousa sobre a capacidade apreciativa de ser afetado ou sensibilizado por prazer ou desprazer ${ }^{3}$. Isto permite concluir que, para investigarmos o sentimento, podemos estudar a faculdade apreciativa do sentimento que é o gosto (e que Kant chamará depois de faculdade de julgar, cabendo a ela ajuizar os estados mentais como prazer ou não). Não por acaso, ao contar a Reinhold ter descoberto princípios a priori para o sentimento, Kant anuncia que se debruçará em uma crítica do gosto ${ }^{4}$.

No início da passagem do parágrafo III, da Primeira Introdução citada há pouco, ("consegue-se por certo descobrir... um sentimento de prazer contido na determinação da vontade"), Kant diz que descobri-

1 Segundo Ricardo Terra, no prefácio às Duas Introduções à Crítica da Faculdade doJuízo, "Já em maio de 1787, quando terminava de escrever a Crítica da Razão Prática, Kant demonstra a intenção de escrever uma Crítica do Gosto. Na carta a LH. Jakob de 11 de setembro de 1787, Kant comenta que a 'Crítica da Razão Prática já está com o editor e imediatamente volto-me para a elaboração da Crítica do Gosto'. 10 trabalho na Crítica do gosto teria começado então na segunda metade de setembro de 1787. Pelo menos até março de 1788 Kant continua a chamar a obra de 'Crítica do gosto' (carta a Reinhold, 7 de março de 1788, AK. X, 505); b) Em maio de 1789, temos uma primeira referência à Kritik der Urteiskraft, da qual a Crítica do gosto é uma parte (cf. carta a Reinhold, 12 de maio de 1789, Ak. Xl, 39) [...]. É, portanto, entre março de 1788 e maio de 1789 que Kant muda os planos de escrever uma crítica do gosto e passa a pensar em uma Crítica do Juízo, que seria mais ampla, pois englobaria, além do belo, também o sublime e a teleologia propriamente dita" (KANT, 1995, p.18).

3 Colocar a questão de uma crítica do sentimento é, pois, colocar a questão da existência de uma faculdade de ser afetado. Trata-se de descobrir uma dimensão de afetividade da mente humana, desligando-a do conhecimento e da moral. Kant chamará tal dimensão afetiva de instância autônoma do Gemut: o Sentimento.

4 A carta a Reinhold nos mostra que a crítica do gosto tinha sido concebida desde o início como uma crítica do sentimento, que investigaria os princípios a priori para o sentimento. $\mathrm{O}$ que significa que Kant procedeu a uma valonização do sentimento, antes ligado à simples validade privada ou à psicologia (e excluído assim da filosofia transcendental), reconhecendo-lhe uma validade comum e conferindo-lhe universalidade e necessidade, dois índices indissoluvelmente ligados ao a priori.

Revista de Filosofia, Curitiba, v. 18 n. 21, p. 11-25, jul./ dez. 2005. 
mos uma vinculação a priori entre as faculdades da mente (a de conhecer e a de apetição) por meio de uma discussão sobre a vinculação do conceito de liberdade (chamado ali de "conhecimento") à faculdade de apetecer (a vontade). O conceito de liberdade é o fundamento objetivo de determinação da vontade, da faculdade de apetecer, (o sentimento de prazer forneceria o fundamento de uma determinação subjetiva da vontade).

Esta formulação soa estranha, já que o conceito de liberdade é um conceito prático, fornecido não estritamente pela faculdade de conhecer, mas pela razão (num sentido prático). Ainda mais estranho é admitir um fundamento subjetivo de determinação da vontade e identificá-lo ao sentimento de prazer. Contornemos tais estranhezas lembrando a ressalva kantiana de que "não é por intermédio do prazer ou desprazer que a faculdade de conhecimento está ligada com a faculdade-de-desejar; pois este não a precede, mas, ou se segue diretamente à determinação desta última ou, talvez, nada mais é do que a sensação dessa determinabilidade da vontade pela própria razão" (KANT, 1995, p. 42). Ainda que não elucide a contento o estatuto do sentimento de prazer enquanto fundamento subjetivo da vontade, tal ressalva nega-lhe a função de vinculação entre as faculdades de conhecer e de desejar. O sentimento de prazer se circunscreveria ao domínio da faculdade de desejar por não fundar uma instância transcendental autônoma, já que ou determinaria a vontade ou se seguiria à determinação da vontade ou resultaria da determinabilidade desta pela razão (pelo conceito racional da liberdade). Kant (1995, p. 42) conclui que o sentimento de prazer (circunscrito à faculdade de desejar) "absolutamente não é um sentimento particular e uma receptividade peculiar que exigisse entre as propriedades da mente, uma divisão particular", ou que exigisse uma nova crítica.

Mas, a continuação da passagem de Kant nos adverte que: "como no desmembramento das faculdades da mente, em geral, está dado incontestavelmente um sentimento de prazer, que, independente da determinação da faculdade de desejar, pode, antes, fornecer um fundamentode-determinação da mesma embora, para sua vinculação com as outras duas faculdades em um sistema, seja exigido que esse sentimento de prazer, assim, como as outras faculdades, não repouse sobre fundamentos meramente empíricos, mas também sobre princípios a priori, então, para a Idéia da filosofia como um sistema será também requerida (embora não uma doutrina, no entanto) uma crítica do sentimento de prazer e

Revista de Filosofia, Curitiba, v. 18 n. 21, p. 11-25, jul./dez. 2005. 
desprazer, na medida em que não está fundado empiricamente" (KANT, 1995, p. 42). Como está dado um sentimento de prazer, que independe da faculdade de desejar, e prescinde de fundamento empírico, será tal sentimento o terceiro termo que vinculará num sistema as duas outras faculdades (a de conhecer e a de desejar). Tal vinculação requer uma "crítica" do sentimento de prazer, cujo estatuto cabe esclarecer.

Para vincular conhecimento e desejo (faculdades superiores), Kant descobre um terceiro termo capaz de realizar esta tarefa. A passagem comentada acima nos mostra que a tentativa inicial de Kant era vincular conhecimento (conceito racional da liberdade) e vontade (faculdade de desejar) e que o meio para isso era um determinado sentimento, aquele do respeito. Como o sentimento do respeito não possui autonomia, foi preciso encontrar outro sentimento dotado de autonomia. Kant descobre então (progressivamente) que "está dado um sentimento" diferente daquele do respeito e capaz de vincular as faculdades.

Recapitulando: a vinculação é o problema filosófico que anima o empreendimento de Kant aqui. O primeiro nível deste problema aparece na Metodologia da Razão Prática e consiste em tornar sensível a razão prática (KANT, 1989, p. 171-182). Para aprendermos a sermos morais precisamos nos tornar sensíveis aos imperativos do dever, vinculando assim as leis morais ao ânimo. O segundo nível aparece com a descoberta de que está dado um sentimento de prazer e desprazer (sem fundamento empírico), cuja crítica será requerida para a Idéia da filosofia em um sistema. E é por isso que Kant conceberá o empreendimento de uma "crítica do gosto".

A preocupação "prática" da Metodologia da Crítica da Razão Prática se transformará assim numa preocupação sistemática. Ao falar em unidade da filosofia, Kant está se referindo à unidade da razão, ou das faculdades superiores, pois no fundamento da filosofia existe um sistema das faculdades superiores (lembremos o título do parágrafo II da Primeira Introdução). Só que cada faculdade superior está referida a uma faculdade da mente (ânimo).

Cada interesse superior da razão funda uma faculdade da mente, do seguinte modo: 1) o interesse expresso na pergunta "o que posso conhecer?' funda uma faculdade-de-conhecer; 2) o interesse expresso na pergunta "o que devo fazer?" funda a faculdade de desejar. Cada interesse, cada faculdade da mente possui uma faculdade superior (que fornece princípios a priori), tendo em vista a realização desses interesses. Temos

Revista de Filosofia, Curitiba, v. 18 n. 21, p. 11-25, jul./dez. 2005. 
assim o entendimento (fornecendo leis à natureza) e a razão (fornecendo leis à liberdade). Ora, como conseguir a unidade da subjetividade, a unidade da razão (em sentido amplo), a unidade da mente, a unidade das faculdades superiores? Esta questão pode ter sido pensada juntamente com a famosa afirmação do final da Crítica da Razão Prática (KANT, 1989, p. 183).

Kant obtém tal unificação pela introdução de um terceiro termo. O projeto da Metodologia da Crítica da Razão Prática se transformará assim no projeto da unidade do sistema, em vista do qual Kant trabalhará com três tópicas ${ }^{5}$. Estando dado um sentimento, podemos, por analogia com o caso do sentimento do respeito, esboçar uma primeira vinculação entre as faculdades de conhecer e de desejar. Como cada faculdade da mente possui uma faculdade que lhe fornece princípios a priori, aquele sentimento dado terá também de possuir uma faculdade superior que lhe forneça princípios a priori.

Como na faculdade de conhecer, segundo a sua faculdade de pensar são dadas ou exigidas três faculdades (razão, faculdade de julgar e entendimento) com funções específicas (KANT, 1995, p. 37). Kant reconhecerá que dependendo de cada interesse da razão este sistema tripartite de faculdades de conhecer assumirá diferentes funções. Assim, na Crítica da Razão Prática, a razão não será mais a faculdade de derivação a partir de princípios, tendo em vista o seu uso regulador, mas a faculdade de princípios, de idéias. $\mathrm{O}$ entendimento, como já sabemos, possui um papel preponderante no conhecimento. Resta à faculdade de julgar que, se possuísse um novo estatuto, talvez pudesse fornecer princípios a priori para o terceiro termo que é o sentimento. Esta argumentação está presente nas duas introduções.

Kant inicia, então, uma crítica do sentimento, do gosto, com a firme intuição de que está dado um sentimento superior. Na consecução desta crítica, ele descobrirá uma faculdade de julgar com funções próprias e esta tomará uma proporção conceitual tão grande que o projeto inicial se transformará em uma Crítica da faculdade do juízo. Um trecho da Segunda Introdução parece respaldar esta nossa interpretação:

5 A tópica dos poderes do ânimo (faculdade de desejar, sentimento de prazer e desprazer, faculdade de conhecer), a tópica das faculdades superiores, puras (razão, faculdade de julgar, entendimento) e a tópica das faculdades do conhecimento que operam raciocínios, juízos e conceitos (mais uma vez: razão, faculdade de julgar e entendimento).

Revista de Filosofia, Curitiba, v. 18 n. 21, p. 11-25, jul./dez. 2005. 
Mas é ainda possível (para julgar segundo a analogia) acrescentar uma nova razão que nos leva a conectar a faculdade do juízo com uma outra ordem das nossas faculdades de representação (o que abrirá a possibilidade da vinculação da tópica das faculdades superiores com a tópica dos poderes da mente) e que parece ser ainda de maior importância que o parentesco com a família das faculdades de conhecimento. Na verdade todas as faculdades da alma ou capacidades podem ser reduzidas àquelas três, que não se deixam, para, além disso, deduzir de um princípio comum: a faculdade de conhecimento, o sentimento de prazer e desprazer e a faculdade de apetição. Para a faculdade de conhecimento apenas o entendimento é legislador, no caso daquela [...], se for considerada em si, sem se misturar com a faculdade de apetição como faculdade de um conhecimento teórico, ser relacionada com a natureza [...]. Para a faculdade de apetição, como faculdade superior segundo o conceito de liberdade apenas a razão [...] é legisladora a priori. Ora, entre a faculdade de conhecimento e a de apetição está o sentimento de prazer, assim como a faculdade do juízo está contida entre o entendimento e a razão. Por isso, pelo menos provisoriamente, é de supor que a faculdade do juízo, exatamente do mesmo modo, contenha por si um princípio a priori e, como com a faculdade de apetição está necessariamente ligado o prazer ou desprazer (quer ela anteceda, como no caso da faculdade de apetição inferior, o princípio desta faculdade, quer, como no caso da superior, surja somente a partir da determinação da mesma mediante a lei moral), produza do mesmo modo uma passagem da faculdade de conhecimento pura, isto é do domínio dos conceitos de natureza para o domínio do conceito da liberdade, quando no uso lógico torna possível a passagem do entendimento para a razão (KANT, 1995, p. 103-104).

Tal passagem traz um movimento argumentativo que podemos perceber invertendo a ordem dos argumentos que apresentamos anteriormente: sendo o termo médio na faculdade de conhecer, a faculdade de julgar poderia funcionar de modo análogo noutro tipo de mediação se ela possuísse um outro estatuto. Mais precisamente, se ela possuir um estatuto de faculdade que fornece princípios a priori, ela poderá vincu-

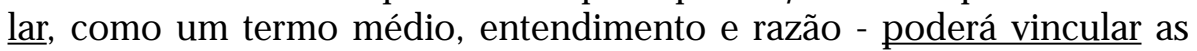
legislações destas duas faculdades por meio de uma legislação "regulativa" fornecida por ela mesma. E como cada faculdade superior se vincula a um poder do ânimo, a vinculação de suas legislações também vincula-

Revista de Filosofia, Curitiba, v. 18 n. 21, p. 11-25, jul./dez. 2005. 
rá estas faculdades do ânimo. Precisamos demonstrar a existência de um sentimento, cabendo à crítica mostrar o exercício de uma faculdade de julgar a priori, vinculando assim a sua legislação com as legislações das outras duas. Trata-se da descoberta de uma faculdade superior (a faculdade do juízo) e da construção de uma instância transcendental da mente humana (o sentimento de prazer).

Analisemos a afirmação kantiana de que "está dado incontestavelmente um sentimento". Será a questão do sentimento moral do respeito que nos permitirá descobrir um caso de conexão a priori entre o sentimento e as duas outras faculdades: "um conhecimento a priori, o conceito racional da liberdade, está ligado à faculdade de desejar donde ela é o princípio determinante e esta determinação é ao mesmo tempo, subjetivamente, um sentimento". Mais do que a mera valorização do conceito de sentimento será a descoberta de um sentimento a priori que movimentará toda a gênese do gosto.

Na Crítica da Razão Prática, Kant vincula o sentimento ora à sensibilidade (não considerada como intuição) ora à razão. O sentimento pode ser um princípio subjetivo do desejar. Na Crítica da Faculdade de Julgar, o sentimento será definido como uma receptividade de uma determinação do sujeito, situando-se, portanto, fora das faculdades de conhecer e desejar, que têm em comum o fato de implicarem uma referência objetiva das representações. Como se dá o movimento entre estas duas concepções? O sentimento do respeito fornecerá os meios para esta transição da faculdade inferior de desejar ao sentimento partilhável ou comunicável. O sentimento é um princípio de determinação da faculdade de desejar, que pode ser determinada não só empiricamente (pelo prazer ou desprazer) como também a priori (pela lei moral).

Para mostrar que há uma razão prática, será necessário criticar todo o poder prático da razão a fim de dotar a faculdade de desejar de um estatuto. Trata-se, pois, de criticar os princípios determinantes da vontade $^{6}$.

6 O trecho da Primeira Introdução que discutimos admite a possibilidade de vinculação entre as faculdades de conhecer e de desejar, mas não por intermédio do prazer, que estaria circunscrito à faculdade de desejar e não fundaria um sentimento particular ou uma receptividade peculiar. Para entendermos isto temos que examinar os aspectos inferior e superior da faculdade de desejar. Kant pretende na Crítica da Faculdade do Juízo separar de direito o prazer e a faculdade de desejar e assim encontrar um sentimento que faça a vinculação entre as faculdades.

Revista de Filosofia, Curitiba, v. 18 n. 21, p. 11-25, jul./dez. 2005. 
A Crítica da Razão Prática opõe o prazer moral ao prazer material, não distinguindo entre "estético", "fisiológico" ou "patológico": "Se uma ação é imediatamente o princípio de um prazer, este é moral; mas se o prazer é a causa da ação esse prazer é físico ou estético". Aqui o "estético" é apenas um dos mais baixos graus do psicológico. O prazer só é mencionado a título de princípio material da faculdade de desejar: "O prazer proveniente da representação da existência de uma coisa é seu único móvel; sem ele, não haveria nem desejo nem matéria da faculdade de desejar". (KANT, 1989, p. 31). Neste primeiro momento, o sentimento de prazer é considerado empírico, psicológico, princípio material da vontade. A noção de prazer se modifica na Crítica da Faculdade do Juízo. Na analítica da Crítica da Faculdade do Juízo, Kant definirá o interesse pela satisfação (complacência) que se conecta com a representação da existência de um objeto ou de uma ação: "Chamamos de interesse a complacência que unimos à existência de um objeto". (KANT, 1993, p.49). A faculdade de desejar é sempre acompanhada por uma satisfação. A satisfação que se conecta necessariamente com o desejo é denominada prazer. Neste primeiro nível de consideração, o prazer se define como "a representação da concordância do objeto ou da ação com as condições subjetivas da vida, isto é, com o poder causal de uma representação com vista à realidade do seu objeto (ou com o poder determinante das capacidades do sujeito à ação para produzi-lo)" (KANT, 1989, p.17). A questão é que a apetição (o desejo) sempre se conecta com o prazer, seja como matéria da faculdade de desejar (este prazer se definiria como empírico, fisiológico, patológico, produzido pela relação da representação de existência do objeto), seja como "prazer prático".

A conexão da faculdade de desejar com o prazer pode se dar de duas maneiras: 1) enquanto determinando o uso desta faculdade; 2) como conseqüência do uso desta faculdade. Esta alternativa funda no âmbito da razão prática dois tipos de interesse: 1) interesse intelectual, que ocorre mediante a razão segundo uma regra; 2) interesse da inclinação, que se torna o fundamento de determinação da faculdade de desejar. A determinação da razão com relação ao interesse pode ocorrer de duas maneiras diversas: ou a razão determina a regra segundo a qual algo pode ser alcançado sobre a base de um interesse, ou ela determina imediatamente o interesse como tal.

No primeiro caso, o prazer torna-se o fundamento determinante do interesse, e a razão representa-se mediante um imperativo hipoté-

Revista de Filosofia, Curitiba, v. 18 n. 21, p. 11-25, jul./dez. 2005. 
tico apenas a condição do fim a ser alcançado. Nas palavras de Kant: "Todos os princípios práticos que supõem um objeto - matéria - da faculdade de desejar como fundamento de determinação da vontade, são, todos eles, empíricos e não podem proporcionar qualquer lei prática. Entendo por matéria da faculdade de desejar um objeto cuja realidade é apetecida. Se o apetecimento para com esse objeto precede a regra prática e é a condição para adotá-la como princípio, nesse caso, digo primeiramente -: esse princípio, então, é sempre empírico" (KANT, 1989, p. 33).

No segundo caso, o prazer torna-se intelectual e o interesse torna-se interesse da razão. Com efeito, se o prazer é apenas uma conseqüência de uma certa determinação anterior da faculdade de desejar, a razão determina sozinha o interesse e seus princípios ou leis, de tal modo que o prazer passa a ser simples conseqüência da determinação da lei.

Nossa reflexão até aqui permite ver que a definição de prazer está circunscrita à faculdade de desejar (vontade). A distinção kantiana entre duas espécies de faculdade de desejar esclarece como o interesse se vincula a uma vontade racional. Uma faculdade de desejar (a inferior) situa-se no âmbito da sensibilidade, e a outra (a superior), no âmbito da vontade ou da razão prática. A faculdade superior de desejar é concebida como uma faculdade de desejar segundo conceitos, cujo arbítrio para fazer ou deixar de fazer algo encontra-se na razão. Ambas as faculdades estão ligadas à satisfação. Só que à vontade, enquanto faculdade de desejar, pode também ser baseada em princípios puros da razão, e mesmo se acompanhada por uma satisfação, pode também tomar a forma de um interesse somente por aquilo que é determinado universal e necessariamente pela razão.

Neste momento, Kant define o prazer como "a representação da concordância do objeto ou da ação com as condições subjetivas da vida, isto é, com o poder causal de uma representação com vista à realidade do seu objeto (ou com o poder determinante das capacidades do sujeito à ação para produzi-lo)" (KANT, 1989, p. 17). Este poder causal da representação na produção de seu objeto faria parte das condições subjetivas da vida, e a representação do acordo destas condições com o objeto produzido se chamaria prazer (trata-se de uma satisfação na produção de um determinado objeto da representação). O poder de causar a realidade dos objetos de suas representações (por meio delas próprias)

Revista de Filosofia, Curitiba, v. 18 n. 21, p. 11-25, jul./dez. 2005. 
permite uma definição transcendental da vida e do sentimento. A vida seria o poder de agir a partir de um princípio interno, de se determinar as mudanças enquanto mudanças de estado. Guillermit nota que "esta definição do prazer o subordina à faculdade de desejar, já que não conhecemos nenhum outro princípio interno que permitiria a mudança de estado senão o desejo" (GUILLERMIT, 1988, p.77). O prazer é colocado no âmbito da faculdade de desejar enquanto representação do acordo do objeto ou da ação com as condições subjetivas da vida (isto é, com o poder causal de uma representação sobre a realização de seu objeto ou a determinação das forças do sujeito no ato de produzi-lo). O prazer será patológico quando preceder o princípio da faculdade de desejar. E será intelectual quando resultar da determinação da faculdade de desejar.

Na Primeira Introdução, encontraremos uma nova definição transcendental do sentimento de prazer: "o prazer é um estado da mente na qual uma representação entra em acordo com ela mesma como razão, seja de lhe conservar simplesmente (porque o estado das forças da mente que se favorecem mutuamente se conserva a si próprio), seja de produzir seu objeto" (KANT, 1995, p. 67-68). Esta definição enriquece a precedente na medida em que a produção do objeto da representação, único ponto retido da primeira definição, torna-se o segundo termo de uma alternativa, na qual o primeiro designa o caso em que a representação é somente o princípio de sua própria conservação. Esta definição rompe o liame entre o sentimento de prazer e a faculdade de desejar, já que podemos reconhecer, nos dois casos em que o prazer é a causa do desejo (patológico) ou o efeito do desejo (prático), duas subespécies da espécie do prazer prático. A outra espécie se chamará prazer simplesmente contemplativo, prazer que não liga nenhum desejo ou interesse à existência do objeto (à qual ele é indiferente, ou "desinteressado", nos termos de Kant), ligando-se apenas à representação do objeto.

A Crítica da Faculdade do Juízo definirá o sentimento de prazer como um estado da mente, separando com isso o sentimento da faculdade de desejar. Ela pôde fazer isso por reconhecer que sentimento é mais do que uma dimensão, meramente empírica, fisiológica, patológica, psicológica (indo além do que ocorria na definição da inclinação, a matéria da faculdade de desejar inferior). Kant conceberá agora o sentimento como a priori, e para isso a noção de respeito cumprirá um papel importante, pois também é um sentimento a priori, embora ligado à razão. Kant percebe que nem todo sentimento é empírico, existe uma

Revista de Filosofia, Curitiba, v. 18 n. 21, p. 11-25, jul./ dez. 2005. 
espécie que é universal e necessário. Vimos numa passagem da Primeira Introdução que a descoberta do móvel da razão prática (o sentimento do respeito) não autorizava concluir que é por meio do prazer e do desprazer que o poder de conhecer está ligado ao poder de desejar. O respeito aparece como distinto dos outros sentimentos. Ele é a expressão da relação que se estabelece entre a lei (tornando-se um móvel da vontade) e o conjunto de nossa sensibilidade. Ora, se todo sentimento fosse empírico, patológico e sensível, como atribuir ao respeito a característica de sentimento?

O respeito depende da representação da lei unicamente segundo sua forma, não segundo seu objeto. Ele é uma espécie de sentimento característica e exclusiva da pura razão prática, não podendo, pois, ser assimilado ao gozo nem ao sofrimento. Ele é um sentimento de prazer que, sendo um sentimento moral, não se reduz a nenhum sentimento patológico. Se ele fosse patológico, não poderíamos buscar seu liame a priori com uma lei qualquer. A admissão de que o respeito é da ordem do sentimento se baseia no fato de que se pode conceber a priori que ele é indissoluvelmente ligado à representação da lei moral em todo ser racional finito. Como este é um ser racional sensivelmente afetado, podemos concluir que a razão possui uma causalidade pela qual ela determina a sensibilidade conforme seus princípios e inspira um sentimento de prazer ou de satisfação pelo cumprimento do dever. Mas como isto acontece? Como um pensamento da razão pode a priori produzir uma sensação de prazer ou desprazer? Aqui fazemos um apelo à causalidade da liberdade que repousa sobre a constituição supra-sensível do sujeito e efetuamos a priori a junção do sentimento como efeito com uma representação considerada como causa. Mas será que podemos derivar a priori de conceitos morais universais o sentimento de respeito? O que a lei moral como móvel produz no Gemüt? O que torna o sujeito determinável por certas representações?

Kant diz que não deduzimos propriamente o sentimento de respeito da Idéia da moralidade como se ele fosse o efeito de uma causa. O que derivamos da moralidade é a determinação da vontade. E aqui vem o argumento que nos interessa: "o estado de ânimo de uma vontade determinada por qualquer coisa é em si já um sentimento de prazer e idêntico a ele, logo não resulta dele como efeito: o que somente teria que ser admitido se o conceito do moral como um bem precedesse a determinação da vontade pela lei; pois então o prazer que fosse ligado 
ao conceito em vão seria deduzido deste como mero conhecimento" (KANT, 1993, p. 67-8). A determinação da vontade pela lei moral já é um estado ou sentimento de prazer, no caso o respeito. Existe uma identidade entre a determinação da vontade e um estado de prazer.

Para isso não determinamos a priori a influência que uma representação dada exerce sobre a mente, pois não se trata de uma passagem da consciência ao sentimento por meio de conceitos, já que consideramos não a relação da idéia da razão (lei moral) ao sentimento (de respeito), mas sim a relação entre a legislação da faculdade de conhecer (razão prática) e a determinação da faculdade de desejar (vontade). É a representação de uma legislação universal do querer que determina a vontade e desperta o sentimento de respeito. Mais importante: esta relação entre as faculdades da mente pode ser sentida porque ela afeta o estado de ânimo. Será nesta determinação objetiva (da faculdade de desejar pela razão) que encontraremos ao mesmo tempo subjetivamente um sentimento de prazer contido na determinação da vontade. Encontramos um sentimento ao lado da determinação objetiva da lei sobre a vontade.

Para explicarmos a transformação da definição transcendental do sentimento, retomemos as duas definições do prazer: 1) "O prazer é a representação da concordância do objeto ou da ação com as condições subjetivas da vida, isto é, com o poder causal de uma representação com vista à realidade do seu objeto (ou com o poder determinante das capacidades do sujeito à ação para produzi-lo)"; 2) "o prazer é um estado da mente no qual uma representação entra em acordo com ela mesma como razão seja de lhe conservar simplesmente (porque o estado das forças da mente que se favorecem mutuamente se conserva a si próprio), seja de produzir seu objeto". A primeira afirma uma afinidade com a faculdade de desejar; a segunda possui dois termos, um dos quais concerne ao sentimento ele mesmo. A consideração acerca do sentimento do respeito permitiu a Kant definir o sentimento como um estado no qual a mente se encontra afetada por meio de uma determinação da faculdade de desejar por meio de uma representação. A idéia central é que a determinação da vontade é um estado de ânimo idêntico ao sentimento. Tal identidade permitirá a Kant ampliar o conceito de sentimento, retirando-o da circunscrição à faculdade de desejar, concedendo-lhe autonomia e configurando-o como um termo médio capaz de vincular as faculdades de desejar e de conhecer. O sentimento aparece, assim, como um estado da mente não subordinado à faculdade de desejar.

Revista de Filosofia, Curitiba, v. 18 n. 21, p. 11-25, jul./ dez. 2005. 
Existe um movimento imanente à Crítica da Faculdade do Juízo que vai do projeto de elaboração de uma "crítica do gosto" ao problema da mediação entre natureza e liberdade. A crítica do gosto é concebida por motivos sistemáticos expressos na necessidade de tornar o ânimo receptivo à lei moral. Na Metodologia da Crítica da Razão Prática, é formulada a questão da sensibilização do ânimo ao dever. Estas questões estão magistralmente registradas na Primeira Introdução: "A crítica do gosto (...) quanto tratada em intenção transcendental, abre, ao preencher uma lacuna no sistema de nossas faculdades-de-conhecimento, uma perspectiva surpreendente e, ao que me parece, muito promissora, em um sistema completo de todos os poderes-da-mente, na medida em que, em sua determinação, são referidos, não somente ao sensível, mas também ao supra-sensível, sem, no entanto deslocar o marco de limite que uma crítica inflexível impôs a este último". (KANT, 1995, p. 83).

A crítica do gosto nasce, assim, de um desejo de empreender um sistema dos poderes do ânimo cuja configuração permitirá colocar a questão de uma receptividade do ânimo ao sentimento moral:

A espontaneidade no jogo das faculdades de conhecimento, cuja concordância contém o fundamento desse prazer, torna o conceito pensado como apropriado à mediação da vinculação dos domínios do conceito da natureza e do conceito da liberdade em suas conseqüências, conforme essa vinculação estimula ao mesmo tempo a receptividade da mente ao sentimento moral (KANT, 1995, p. 128).

A crítica do gosto fornecerá a Kant, então, uma sistematização das faculdades do ânimo, incluindo entre elas uma receptividade ao sentimento moral. Ela, portanto, constituirá um terceiro termo na tópica dos poderes do ânimo ao lado da faculdade de conhecer e da faculdade de apetição o que permitirá vinculá-las e ao mesmo tempo colocar a questão da receptividade ao sentimento moral.

A “estética” é, então, uma determinada espécie de receptividade do ânimo. Será para a construção transcendental desta receptividade autonomizada do conhecer e do apetecer que se procederá a uma fundamentação dos juízos estéticos. A questão da receptividade do ânimo ao sentimento moral levará Kant a colocar a questão da fundamentação

Revista de Filosofia, Curitiba, v. 18 n. 21, p. 11-25, jul./dez. 2005. 
dos juízos estéticos, o que o levará à formulação da problemática da passagem da natureza à liberdade, cujo desdobramento se dará na Crítica da Faculdade de Julgar Teleológica ${ }^{7}$.

\section{Referências}

DUMOUCHEL, Daniel. "La découverte de la faculté de juger réfléchissant": Kant-studien, n. 85, p. 419-442, 1994.

GUILERMIT, Louis. L'élucidation critique du jugement de goût selon Kant. Paris: CNRS. 1986. p. 295.

KANT, Immanuel. Crítica da faculdade do juízo. Tradução de Valerio Rohden e António Marques. Rio de Janeiro, RJ: Forense Universitária, p. 381, 1993.

. Primeira Introdução à Crítica do Juízo. Traduzido por Rubens Rodrigues Torres Filho. In: Crítica da razão pura e outros tex tos filosóficos. São Paulo, SP: Abril Cultural, 1974. p.257-297. (Col. Os Pensadores, 25),

. Duas introduções à crítica do juízo. Organização de Ricardo Terra. São Paulo, SP: Iluminuras, 1995. 132p.

. Crítica da razão prática. Tradução de Artur Morão. Lisboa: Edições 70, 1989. 192p.

Recebido em/ Received in: 19/01/2005

Aprovado em/ Approved in: 23/06/2005

${ }^{7}$ A Crítica da Faculdade do Juízo é uma obra composta de uma "crítica do gosto" ampliada em uma crítica da faculdade de julgar. O projeto de se vincular os poderes do ânimo (faculdade de conhecer e faculdade de apetição) por meio de um termo médio (a faculdade do sentimento) de forma a tornar o ânimo receptivo à lei moral se explicita em termos de vinculação entre as legislações fornecidas pelas faculdades que fornecem princípios a priori a estes poderes e, como Kant, procede a uma articulação de materiais previamente elaborados com as conquistas obtidas enquanto escreve ou enquanto pensa escrevendo, estes dois níveis de mediação ficam muitas vezes superpostos no texto.

Revista de Filosofia, Curitiba, v. 18 n. 21, p. 11-25, jul./dez. 2005. 